Original Research

\title{
Monitoring Soil Salinity Changes, Comparison of Different Maps and Indices Extracted from Landsat Satellite Images (Case Study: Atabieh, Khuzestan)
}

\author{
Fatemeh Golabkesh $^{1,2}$, Navid Ghanavati ${ }^{2}$, Ahad Nazarpour ${ }^{3 *}$, Timmor Babaei Nejad ${ }^{2}$ \\ ${ }^{1}$ Department of Soil Sciences, Khuzestan Science and Research Branch, Islamic Azad University, Ahvaz, Iran \\ ${ }^{2}$ Department of Soil Sciences, Ahvaz Branch, Islamic Azad University, Ahvaz, Iran \\ ${ }^{3}$ Department of Geology, Ahvaz Branch, Islamic Azad University, Ahvaz, Iran
}

Received: 18 February 2020

Accepted: 3 June 2020

\begin{abstract}
Soil salinity is the dominant process in the degradation of arid and semi-arid soils, which in turn reduces crop yields, increases erosion, and exacerbates desertification. In recent years, soil salinity has affected much of the land in the Atabieh area located in the west of Khuzestan province in Iran. The purpose of this study was thus to evaluate and map soil salinity changes in the region over 15 years using Landsat 7 and 8 satellite images. To that end, the spectra of saline soils in the study area were extracted from the satellite data, and after the initial pre-processing in EVNI software version 5.3, the SI1, SI2, SI3, BI, NDVI, and NDSI indices were prepared. Using the supervised classification method, the salinity map with four different classes was then plotted in Arc GIS version 10.2, and the changes in saline soil area were investigated. Moreover, field surveys, surface soil sampling, soil EC measurement and identification of available minerals were performed by X-ray diffraction (XRD) technique and satellite images. Among the studied indices, the BI index with the highest correlation (0.71) was considered as the best index, and NDVI with the correlation coefficient of 0.35 at the $95 \%$ confidence level, was the best index for vegetation cover. Examination of changes in BI index by Landsat 7 images showed that the non-saline land area decreased from 1023.54 ha in 2000 to 143.43 ha in 2010, while the area with medium salinity increased by $14.57 \%$. Besides, the salinity severity in the NDVI index had a growth rate of $72.86 \%$. In turn, XRD studies confirmed the presence of abundant evaporate minerals (Halites, Calcite and Dolomite) corresponding to the values (real numbers) of salinity and mineralogical maps obtained from the Landsat 8 images.
\end{abstract}

Keywords: Landsat Satellite Images, Remote Sensing, Salinity Index, Soil Salinity, Iran

*e-mail: Ahad.nazarpour@gmail.com A.nazarpour@iauahvaz.ac.ir 


\section{Introduction}

Soil salinity is the process of enriching the soil with soluble salts, which in turn results in the formation of saline soils [1-2]. This process is becoming a serious problem for agriculture in irrigated areas [3]. In effect, saline soil conditions have resulted in a significant decrease in the value and productivity of a vast land area worldwide [4]. Salinity usually occurs in irrigated soils due to the accumulation of soluble salts resulting from the continued use of irrigation water containing high or medium amounts of soluble salts [5-6]. The main problem in this regard relates to arid and semiarid regions, including the degradation of soil and desertification [7-8]. Soil salinity is, indeed, a significant form of land degradation in agricultural areas where knowledge of its extent and severity is needed to plan and implement effective soil reclamation programs [9-10]. Irrigation, evaporation of moisture from the surface or low depth in soil profile and inadequate annual rainfall, in turn, cause the accumulation of salt in the root zone of the plant and, ultimately, lead to the excessive accumulation of salts in the soils of arid and semi-arid $[5,11]$. In these areas, irrigation is essential to increase agricultural production to meet the needs of the population [3-4]. However, irrigation is technically complex and costly and requires extensive management, and failure to apply efficient water management principles may result in water loss [12-13]. Excessive irrigation and inadequate drainage can, in turn, lead to flooding and soil salinity, which may reduce soil productivity, and eventually would result in the loss of arable lands. Therefore, the development of technology to control and reduce soil salinity is one of the most important issues in new agriculture [13-15].

Soil salinity limits different patterns of agricultural land use [16-17]. This is, indeed, a severe environmental hazard affecting the growth of many crops [18-19]. In effect, areas with medium salinity account for about 20 percent of the world's irrigation area, while this figure rises to more than 30 percent in arid and semi-arid countries [19]. Saline surfaces have high dynamics, making the identification of saline soils, and monitoring soil salinity process a difficult undertaking [20-21]. This is because the spectral, spatial, and temporal characteristics influence soil salinity over time [22-23]. Indeed, the study of continuous spatial changes in environmental variables cannot be readily accomplished by the usual methods of statistical analysis [24-26].

Remote sensing data are currently used to map salinity and monitor soil salinity changes [5, 27]. In effect, multispectral satellite sensors measure and record the magnitude of electromagnetic radiation from the earth [28]. The intensities of the reflected radiation from the phenomena are, indeed, recorded in different spectral ranges and used to identify different effects [7]. The most important factor in applying this technique is its cost-effectiveness and time-saving, as well as the possibility of providing up-to-date and high-precision global coverage in satellite imagery $[9,17]$.

Many studies have been already conducted on the use of remote sensing data in soil salinity assessment, including the recent methods of soil salinity spectral mapping techniques by [9], which focused on the praline soils of the United Arab Emirates. In their study, through spectral analysis, a new soil rich in anhydrite $\left(\mathrm{CaSO}_{4}\right)$ was observed in praline coastal fields in the United Arab Emirate. These observations led to the inclusion of a new soil type in the USDA classification. Studying the spatial distribution of these saline and praline soils in the UAE is, indeed, very important, particularly in the saline soils of the study area which has a great impact on the quality of drainage water and its salinity as it is still used in rural areas for agriculture and animal consumption.

[29] used three Landsat Thematic Mapper and Enhanced Thematic Mapper Plus satellite images taken over fourteen years and combined them with field observations to predict salinity changes by the supervised classification method and visual interpretation. They concluded that soil salinity in the study area had decreased.

Using Normalized Difference Salinity Index to measure soil salinity, [30] selected and evaluated several indices that had the highest response to salinity, based on the reports from various studies conducted on plants and mineral salts. The images used in their study were Landsat satellite images orbiting the Earth once every 99 minutes. Landsat satellite images are mainly useful for studies on agriculture, geology, forestry, mapping, and research on global change.

Similarly, [31] used Enhanced Thematic Mapper Plus sensor data to provide digital maps of gypsum and saline-sodium soils in the San Rafael area of Colorado. According to the results, the areas with gypsum soils could be identified using bands 5 and 7 of the Normal Difference Ratio model. The accuracy of this technique using the field evaluation was, in turn, determined to be about $87 \%$ for gypsum soils and $50 \%$ for sodium soils. They also concluded that Normal Difference Ratio model could be easily applied to map the soil digitally in areas with different reflections resulting from different effects.

In the present study, preliminary field surveys determined the status of vegetation cover and soil salinity to identify the capability of source separation in hyperspectral imagery. The reference spectrum was, then determined to provide image analysis. The Landsat 8 satellite imagery acquired in early November 2015 was then compared with Landsat 7 satellite imagery from three periods $(2000,2005$ and 2010) aiming at evaluating whether drylands are suitable for mapping soil salinity indices and show good estimation.

Since the salinity of arid lands affects large areas in the region, it is thus important to identify and investigate the methods of salinity extraction using spectral images. These methods are continuously applied to 
several images to determine the salinity of the area based on soil salinity indices extracted. Following [32], the existing images are commercially analyzed, so that managers can use the efficient techniques developed for salinity mapping and monitoring. This analysis was, thus, performed to identify the spectrum of the images, related to the salinity indices, and to confirm the corresponding distribution maps. The salinity index maps were then validated by extensive field sampling.

Many land areas in Khuzestan province in southwestern Iran is facing severe salinity, and the existing soil maps are not responsive to the current needs of the region due to their small scale coverage and age. Indeed, the dynamic properties of soil salinity, climate change, and the salty bed of the region have caused changes in the levels affected by the salts. Therefore, salinity mapping in this study using a new method such as Landsat satellite images with a high spatial and spectral resolution of a large-scale area is of particular importance. The present study thus intends to use satellite imagery to monitor soil salinity, map salinity levels, and investigate the trend of salinity changes during 2000-2015 in Atabieh, Khuzestan province.

\section{Material and Methods}

\section{Study Area}

The study area is located between $48^{\circ} 06^{\prime} 21^{\prime \prime}$ and $48^{\circ} 11^{\prime} 31^{\prime \prime}$ eastern longitudes and northern latitudes $31^{\circ} 26^{\prime} 20^{\prime \prime}$ and $31^{\circ} 28^{\prime} 56^{\prime \prime}$ in the west of Khuzestan province in southwestern Iran (Fig. 1). Its approximate area is 5000 hectares and has an average elevation of 10 meters above sea level. In terms of the watershed management division in the country, it is considered as a sub-basin from the lower part of the Karkheh Dam watershed basin. The parent materials of these soils are quaternary sediments that, in some regions, sands are mixed with river alluvium [26]. In the central part of Karkheh River, sedimentary rocks such as calcareous sandstones, gypsum marls, colored siltstone with gypsum, silt marl, mostly calcareous conglomerates, conglomerate sandstone, and in the smaller part of the river path limestone and shale together with thick salt sediments and marl pass. These sedimentary rocks are known for their effects on salinity and alkalinity of the soils and groundwater in the region. From the geomorphologic point of view, the studied sediments with very low overall slope $(0-2 \%)$ had river alluvial plain unit (based on the reports of field experiments and leaching studies and land modification of irrigation and drainage networks of Hufel plain in Khuzestan Province, 2007).

The average annual rainfall during the period 1995-2015 was $190 \mathrm{~mm}$, the average annual temperature was $23.5^{\circ} \mathrm{C}$, and its climate was warm and dry based on Domartan classification. The soil thermal and humidity regimes are hyperthermic and aridic, respectively. Most precipitation is in early winter, and then there is a relatively long, warm and dry season. Despite high groundwater levels, poor drainage, high evapotranspiration, dominant western winds

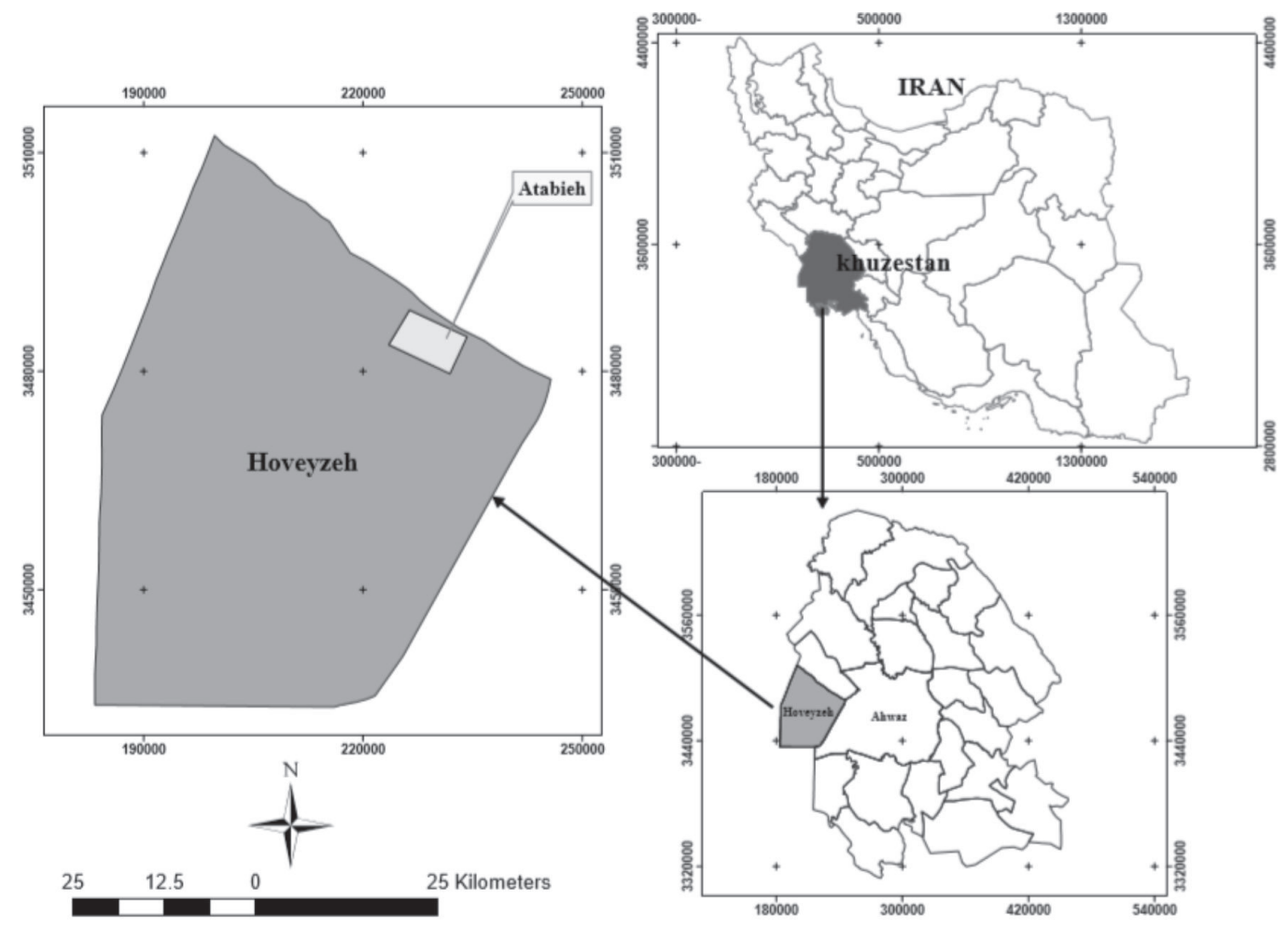

Fig. 1. Location of the study area. 
Table 1. Results of physical and chemical properties of soil in the study area.

\begin{tabular}{|c|c|c|c|c|c|c|}
\hline Variable & Unit & Minimum & Maximum & Average & Median & Mode \\
\hline EC & $\mathrm{dS} / \mathrm{m}$ & 4.91 & 74.00 & 25.40 & 20.02 & 46.70 \\
\hline $\mathrm{pH}$ & - & 7.10 & 8.50 & 7.73 & 7.80 & 7.80 \\
\hline SAR & - & 5.67 & 170.41 & 29.49 & 24.75 & 14.11 \\
\hline Soil thickness & $\mathrm{Cm}$ & 180 & 180 & 180 & 180 & 180 \\
\hline Sand & $\%$ & 2 & 48 & 13.22 & 10 & 8 \\
\hline Silt & $\%$ & 17 & 66 & 39.75 & 40 & 39 \\
\hline Clay & $\%$ & 16 & 65 & 47.04 & 47 & 47 \\
\hline
\end{tabular}

(from the deserts of Iraq and Saudi Arabia), cause the accumulation of minerals and the formation of saline and sodium soils in the region. According to [33], the soils of this region are classified as aridisol and entisol, according to the American soil classification [34].

According to Table 1, The texture of the soils in the region is often dense, which is of silty clay loam type at the surface and clay silty at the depth. Much of the land in the region is, currently, not cultivated due to the excessive salinity and sodium, and vegetation, except in irrigated and drained areas, is salt-tolerant plants such as gramines, alhagi, scolymus maculatus (compositae), salicernia, etc. [35]. Fig 2. shows an overview of the study soils in the study area.

\section{Field Operation and Sampling}

Once the study area was selected based on satellite imagery, 1: 250,000 topographic maps of the area, and ground visit, we designed and implemented a sample cell network with dimensions of $750 \times 750 \mathrm{~m}$ for surface soil sampling. GPS determined the coordinates of each point; then, the sampling was done from each location by auger at a depth of $30 \mathrm{~cm}$ from the soil surface at a distance of $1000 \mathrm{~m}$ from September 15 to October 15, 2015. Fig. 3. shows the distribution of sampling points.

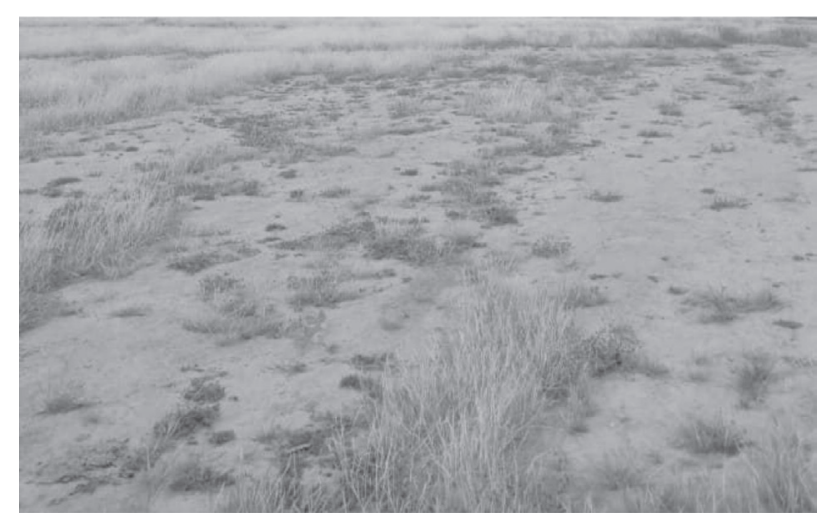

Fig. 2. View of surface saline soil in the study area.

\section{Laboratory Analyses}

A total of 98 soil samples from the selected sites were crushed after drying in open air and passed through a $2 \mathrm{~mm}$ sieve. The electrical conductivity of the samples was, then measured by a conductometer, and a $\mathrm{pH}$ meter was, in turn, used to measure $\mathrm{pH}$ [36]. X-ray diffraction analysis as a quick way to detect the type of material, its phase, and crystalline properties was used. For this analysis, it is necessary to use a wellpowdered, and homogeneous soil, or a uniform film should be prepared. X-ray diffraction was measured using a Philips machine (Zpert400 model). Philips PC APD software was, in turn, used to identify minerals and detect X-ray diffraction diagrams.

\section{Data Processing}

To identify the saline soils by remote sensing method, depending on the latitude and longitude of the study area, the path and row numbers of the satellite image were determined. Accordingly, the study area is located in the path number 166 and row 38, and in the 39R zone in the Urchin Tracking Module coordinate system.

Pre-processing of the extracted satellite images (geometric correction, radiometric correction, and atmospheric correction) was performed in ENVI software version 5.3. In this study, Internal Average Relative Reflectance (IARR) method was used to normalize images using an average image spectrum, convert spectral data to relative reflections in areas where there is no land measurement or little information from the region. In this method, the mean spectrum was calculated for the input image and was used as the reference spectrum. The topographic maps of the Mapping Organization were also used as a reference for land reference images.

Principal component analysis (PCA) methods were also used to obtain bands with maximum information and least dependence. The new composite images were then made from 3 Landsat 7 and 8 satellite bands. Table 2 presents how the various bands are combined to create the required indices in this study. Indeed, the 


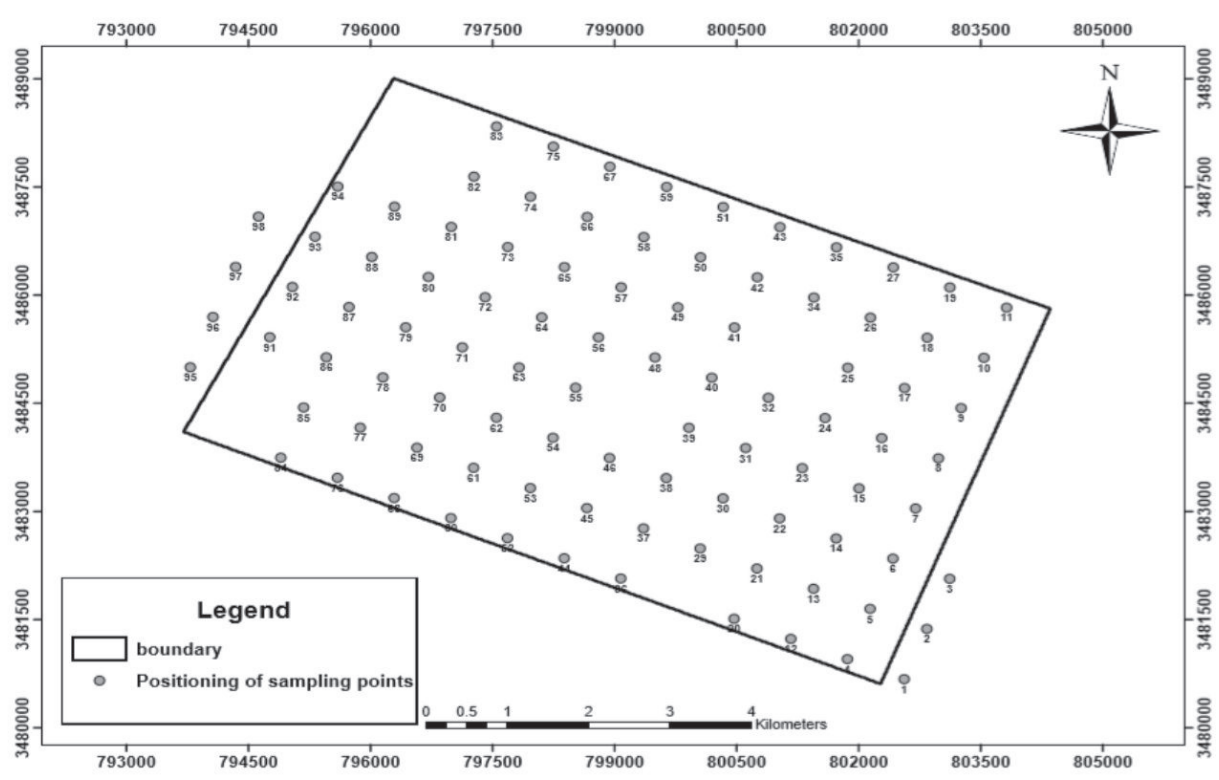

Fig. 3. Distribution of sampling site locations in the study area.

bands were combined to highlight the saline soils from other areas.

$\mathrm{SI}_{1}$ and $\mathrm{SI}_{3}$ as soil salinity indices were calculated from the combination of green and red bands, while $\mathrm{SI}_{2}$ as another soil salinity index was calculated by green, red and near-infrared bands so as to determine soil salinity. NDSI (Normalized Difference Salinity Index) is used to detect saline and non-saline soils, NDVI (Normalized Difference Vegetation Index) is an indicator of a plant's health based on how a plant reflects different light waves, and BI is the brightness index. To calculate them, we used near-infrared and red bands.
The salinity comparison process was performed in two parts. In the first phase, Landsat 8 satellite images were taken on August 3, 2015, almost simultaneously with field surveys. The reason for this slight delay was that sampling in the vast study area was time consuming and the satellite images were updated. In the second part, Landsat 7 satellite images from August 1, 2001, May 30, 2005, and August 29, 2010 were extracted.

It should be noted that each pixel of Landsat 7 and 8 satellite imagery is $30 \mathrm{~m}$ by $30 \mathrm{~m}$ on earth. Therefore, each time the composite sample is collected, the information of ranges of 9 pixels, 90 meters in length,

Table 2. Composition of bands and indices used in the research.

\begin{tabular}{|c|c|c|c|}
\hline Row & Index & Index definition & Source \\
\hline 1 & ${ }^{1} \mathrm{SI}_{1}$ & $\sqrt{\mathrm{GR}}$ & {$[37]$} \\
\hline 2 & ${ }^{2} \mathrm{SI}_{2}$ & $\sqrt{\mathrm{G}^{2}+\mathrm{R}^{2}+\mathrm{NIR}^{2}}$ & {$[38]$} \\
\hline 3 & ${ }^{3} \mathrm{SI}_{3}$ & $\sqrt{\mathrm{G}^{2}+\mathrm{R}^{2}}$ & {$[6]$} \\
\hline 4 & ${ }^{4} \mathrm{BI}$ & $\sqrt{\mathrm{R}^{2}+\mathrm{NIR}^{2}}$ & $(\mathrm{R}-\mathrm{NIR})$ \\
\hline 5 & ${ }^{5} \mathrm{NDVI}$ & $\frac{(\mathrm{R}+\mathrm{NIR})}{(\mathrm{R}-\mathrm{NIR})}$ & {$[39]$} \\
\hline
\end{tabular}

G, R and NIR are the third (green) and fourth (red) and fifth (near-infrared) spectral bands of Landsat 8, respectively. SI1, SI2 and SI3 (salinity indices), BI (Brightness index), NDVI (normalized difference vegetation index) and NDSI (Normalized Difference

Salinity Index).

1 - Salinity Index 1

2 - Salinity Index 2

3 - Salinity Index 3

4 - Brightness Index

5 - Normalized Difference Vegetation Index 
and 8100 square meters, or 0.8 ha, is gathered. The overall Root Mean Square Error (RMSE) in this study is very low, and it is at about 0.5 pixels.

The layering of ground control points, including descriptive salinity information of soil samples, along with raster images of banding compounds made in the geographic information system (GIS) environment, were summoned and mounted. On the images of banding compounds, a mean of 9 pixels was extracted around each sampled point in the field operation. Data extracted from main bands and indices along with salinity data of soil samples were then entered into SPSS software. After normalizing and removig irrelevant data from the data set, Fundamental statistical analysis was followed using the Pearson correlation test.

Besides, the correlation between the data was drawn in Excel software and the accuracy of the estimations was evaluated. Finally, the pixel value of the regression equation obtained between the satellite image indices and the measured values at all locations was generalized to the entire land surface. The results of the reflectance brightness value of each indicator were then determined as image outputs.

Having specified different bands to classify and map the salinity levels, the corresponding pixels of the sample points for each class were introduced as training data for each class. The satellite image classification was introduced based on [1] with 4 different classes: no salinity (0-4 dS/m), low salinity (4-8 dS/m), medium salinity (8-16 dS/m), high salinity (over $16 \mathrm{dS} / \mathrm{m}$ ).

The satellite image classification which was based only on the best false color composite with a set of instructional samples had high accuracy in all 4 different classes. As a result, the study of the values of different salinity classes showed that the possibility of separating non-saline soils (salinity less than $2 \mathrm{dS} / \mathrm{m}$ ) from soils with very low salinity (2-4 dS/m) was weaker than the possibility of separating the two groups from saline soils in the study area. In effect, soils with a wider salinity range have a higher average reflection than other soil groups in all reflective bands.

The supervised classification was, in turn, performed by maximum likelihood, minimum distance, and Mahalanobis distance. Then, based on the correlation of spectral value of different bands with soil electrical conductivity parameter, unclassified pixels were linked to one of the cited spectral classes. The initial classified images were evaluated for the classification accuracy using error tables. Then, the total accuracy criteria and kappa coefficients were calculated for them. After achieving the desired accuracy of the classified images, the polygons of different classes of soil electrical conductivity were presented in the same 4 salinity classes provided by Arc GIS 10.2 software. This way, the different classes were extracted from Landsat 7 and 8 satellite images. Using the best band composition selected from Landsat 8 satellite images in 2015, the diversity and estimation of the quantities of minerals and salt compositions in the soil were also identified and drawn in the mineralogical map by Arc GIS software 10.2. The spectral reflection then separated the types of minerals.

\section{Results and Discussion}

Table 3 presents the numerical value statistics of the 9 cell units of raster images of the 1 to 7 Landsat 8 bands for this study. The pixel values at the lowest to maximum spectral values represent numbers 0.28 to 1.56 , respectively. The lower the number, the higher the salinity level, indicating high salinity in the area. Therefore, considering the optimal exponential factor and analyzing the data into the main components, the fourth, fifth, and seventh bands (4 5 7) which were significantly correlated with the soil salinity, were chosen as the best band composition. Saline areas due to the color of their soil surface and their softer surface than the non-saline soils have a higher reflectance value at these wavelengths. Therefore, the spectral value of these bands can be used to measure the soil salt content and mineralogy.

Soil salinity data at 98 selected points in the region, along with the numerical values of each index and band composition at 87 points were transferred to Excel software and the regression curves and equations for each of the studied indices were drawn (Fig. 4). According to these graphs, in the fitted models, the

Table 3. Characteristics of the bands used for Landsat satellite 8 .

\begin{tabular}{|c|c|c|c|c|c|}
\hline Band number & Spatial Resolution $(\mathrm{m})$ & Minimum & Maximum & Mean & Standard Deviation \\
\hline 1 & 30 & 0.79 & 1.34 & 1 & 0.057 \\
\hline 2 & 30 & 0.71 & 1.39 & 1 & 0.073 \\
\hline 3 & 30 & 0.64 & 1.48 & 1 & 0.095 \\
\hline 4 & 30 & 0.48 & 1.47 & 1 & 0.011 \\
\hline 5 & 30 & 0.41 & 1.35 & 1 & 0.096 \\
\hline 6 & 30 & 0.31 & 1.34 & 1 & 0.0113 \\
\hline 7 & 30 & 0.28 & 1.56 & & 0.0143 \\
\hline
\end{tabular}


a)

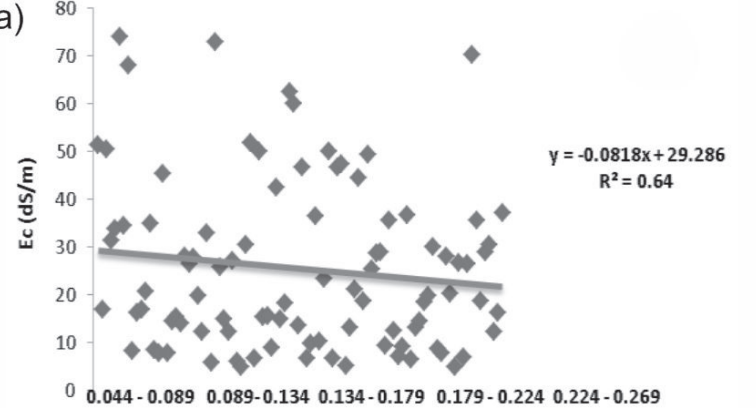

$\mathrm{Sl}_{1}(\mathrm{DN})$

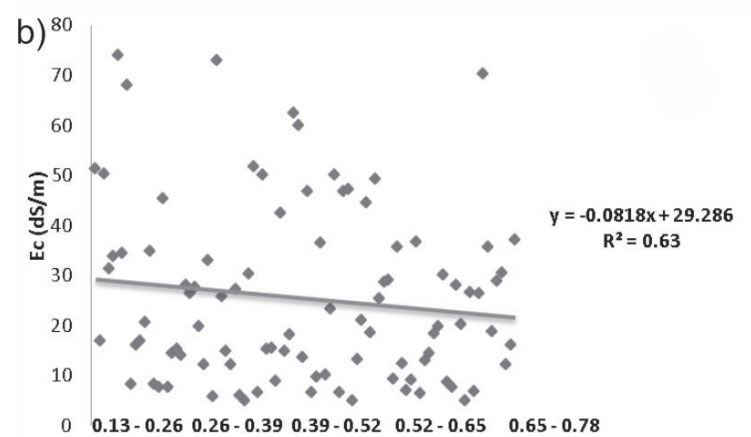

$\mathrm{SI}_{2}$ (DN)

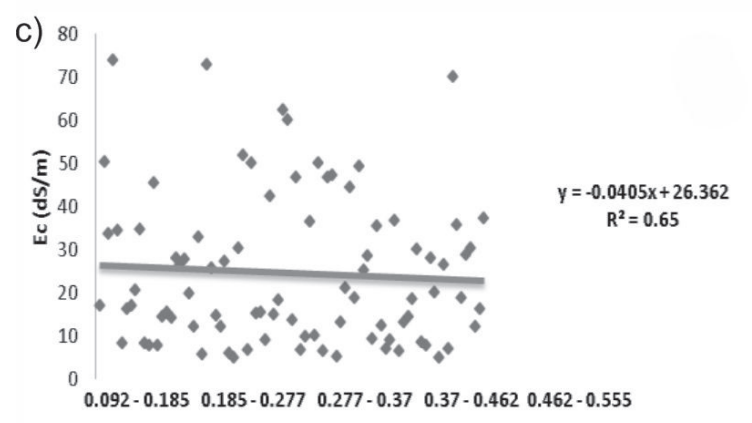

$\mathrm{SI}_{3}(\mathrm{DN})$
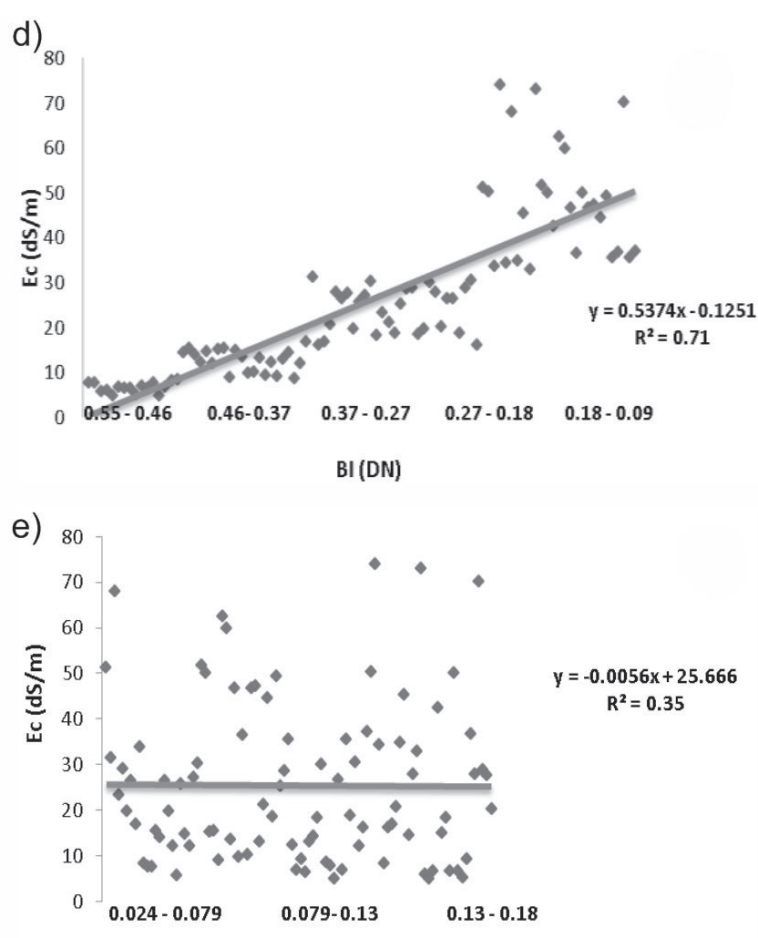

NDVI(DN)

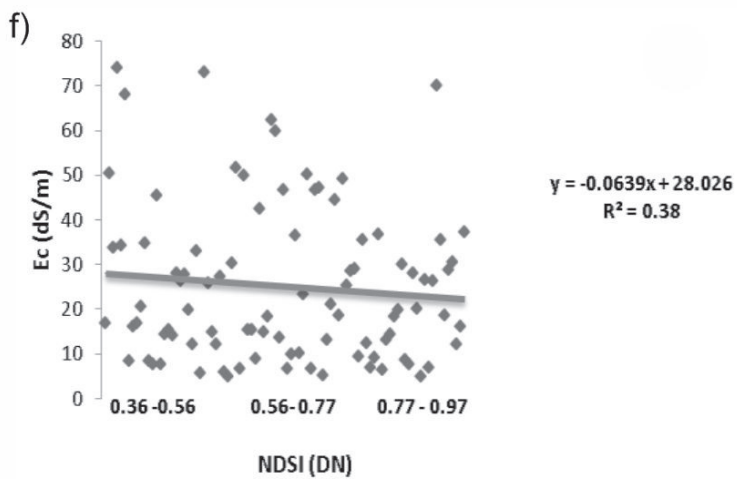

Fig. 4. Correlation of soil electrical conductivity (EC laboratory results) with the studied parameters: a-SI1 index, b-SI2 index, c-SI3 index, $\mathrm{d}-\mathrm{BI}$ index, e-NDVI index, and f-NDSI index.

digital values of the reflections in the images obtained by combining the different bands were considered as the dependent variable, and the amount of salinity measured in the soil samples was considered as independent variables.

The results showed that based on the slope and width from the source, for each increase of salinity in $\mathrm{dS} / \mathrm{m}$, the value of each index changes with a specific slope. The amount of values stored in each cell of raster images is usually influenced by the amount of moisture, changes in flatness and roughness of the surface, shade, amount of soil organic matter, and vegetation. The interplay of these factors and the difficulty of separating the independent effects of each of them often cause problems in such studies [40].

Of the six regression relationships of salinity data in the region with the studied indices, only the brightness index had a positive coefficient (slope), while for other indices, a negative coefficient was obtained. In models with positive regression coefficients, the saline points had a larger cellular value, and in models with negative regression coefficients, the cellular value decreased with increasing soil salinity.

Overall, the Brightness Index had a positive and significant relationship with soluble sodium, calcium, and magnesium. The inverse association of some indices with salinity was for the reason that most of such indices used near-infrared band. In effect, as salinity increased, the spectral value of the near-infrared band decreased [41]. Moreover, the Normalized Difference Vegetation Index had a significant negative correlation with soluble sodium, calcium, and magnesium at a $95 \%$ confidence level. [42] suggested that this negative correlation is logical because the amount of vegetation decreases, as the salinity level increases.

Interpretation of regression coefficients also showed that the Brightness Index with the interpretation coefficient of 0.71 , and then the Salinity Index 3, 
Table 4. Pearson correlation between salinity indices and soil electrical conductivity.

\begin{tabular}{|c|c|c|}
\hline $\begin{array}{l}\text { Index } \\
\text { name }\end{array}$ & & $\mathrm{Ec}(\mathrm{dS} / \mathrm{m})(0-30 \mathrm{~cm})$ \\
\hline \multirow{3}{*}{ SI1 } & Pearson Correlation & ${ }^{*} 0.021$ \\
\hline & Sig. (1-tailed) & 0.424 \\
\hline & Number & 87 \\
\hline \multirow{3}{*}{ SI2 } & Pearson Correlation & ${ }^{*} 0.035$ \\
\hline & Sig. (1-tailed) & 0.347 \\
\hline & Number & 87 \\
\hline \multirow{3}{*}{ SI3 } & Pearson Correlation & ${ }^{*} 0.012$ \\
\hline & Sig. (1-tailed) & 0.457 \\
\hline & Number & 87 \\
\hline \multirow{3}{*}{ BI } & Pearson Correlation & ${ }^{*} 0.026$ \\
\hline & Sig. (1-tailed) & 0.406 \\
\hline & Number & 87 \\
\hline \multirow{3}{*}{ NDVI } & Pearson Correlation & ${ }^{*} 0.115$ \\
\hline & Sig. (1-tailed) & 0.145 \\
\hline & Number & 87 \\
\hline \multirow{3}{*}{ NDSI } & Pearson Correlation & ${ }^{*}-0.001$ \\
\hline & Sig. (1-tailed) & 0.498 \\
\hline & Number & 87 \\
\hline
\end{tabular}

* Means that there is a significant relationship at $95 \%$ confidence level.

Salinity Index 1 and Salinity Index 2 with coefficients of $0.65,0.64$ and 0.63 , respectively, had the highest interpretation coefficients for the prediction of soil salinity changes at the ground control points. According to [43-44], the best ratio for the expression of soil properties affected by solutes was the Brightness Index ratio. The low correlation coefficient and interpretation coefficient in the Normalized Difference Vegetation Index indicates a low vegetation cover in the area and high soil salinity.

In the saline soils of Atabiyeh region with heavy and semi-heavy textures, the toxicity of some soluble salts and the reduction of osmotic pressure reduced water absorption, yield and growth of the crop and rangeland plants in the region. Besides, the presence of saline plants (halophytes) in the region can be indicative of soil salinity. Normally, plants that are unhealthy or affected by salinity have less photosynthetic activity. This, in turn, causes them to reflect more visible light and less near-infrared spectrum.

Using Landsat satellite digital data, [45] study of salinity changes in Ghavand soils of Hamadan province showed a significant but negative correlation of Normalized Difference Vegetation Index with soil salinity at a $95 \%$ confidence level. They also maintained that the increased solute concentration and the adverse effects of salt on plant physiology resulted in a decrease in the percentage of vegetation on the soil surface.

Another reason for the low interpretation coefficient of this index and the ground data is the existence of roads and residential areas (miscellaneous lands) next to the lands studied. Pearson correlation coefficient was also used to examine more closely the relationship between salinity indices and soil Ec (Table 4). Based on the results of Table 4, it can be seen that all the indices are significant at a $95 \%$ confidence level. It should be noted that the accuracy of the indices for soil salinity measurement in each region varies according to the type and amount of soil salinity as well as the type of satellite data. Therefore, the accuracy of these indices should be measured and calibrated so as to study and measure soil salinity in each region [5, 17]. Since both Brightness Index and Normalized Difference Vegetation Index indices showed the best expression in salinity expression of the soils of the study area due to their highest and lowest correlation coefficients with the electrical conductivity, the salinity index map and the saline soil map of Atabiyeh region were provided for these two indices only, and the salinity changes over the 15 years were only examined in the two indices.

The comparison of soil salinity index maps during 2000, 2005, and 2010 (Fig. 5 and Fig. 6) show that the area of all soil salinity classes in the 2010 index images has changed slightly compared to the preceding years. Besides, most of the changes are related to the reduction of non-saline land class area and the development of saline land. According to the data in Table 5, the area of non-saline lands ( $\mathrm{S} 0$ class) in both indices decreased by approximately $17 \%$ between 2000 and 2010. Following the decrease in the non-saline land area, the land area in other classes increased, as the area of S1 and S2 classes in Brightness Index increased by $9.29 \%$ and $14.57 \%$, respectively. That is, most non-saline lands became saline over the 10 years. In effect, the increase in the concentration of solutes changed the soil salinity class to low to medium, and medium to high salinity classes. $[40,44]$ in their study entitled as mapping spatial variability of soil salinity using remote sensing data and geostatistical analysis: a case of Shadegan, Khuzestan, reported an increase in the area of high salinity class from 1990 to 2015.

The main reason for this is the inadequate management of irrigated lands, land use changes, and the abandonment of low-yield irrigated lands. The negative balance of groundwater aquifers increased solute accumulation at the soil surface during the hot seasons, and a severe quantitative and qualitative loss of these resources can be due to traditional irrigation methods and inadequate water use management in the area.

The results of the chemical test of the Karkheh River water sample and the groundwater of the study area, which was conducted at the same time as this study, 

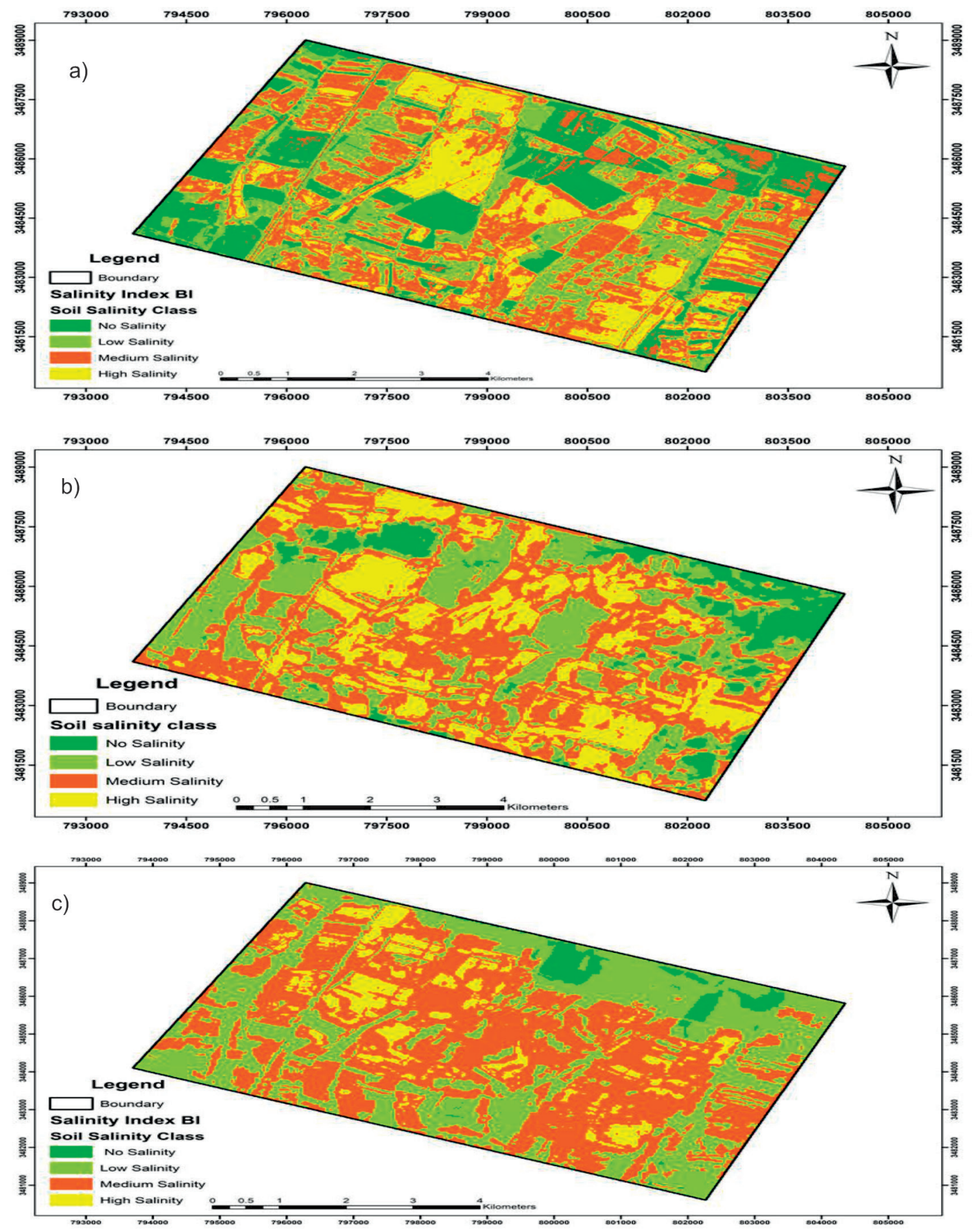

Fig. 5. Map of BI index for the years a) 2000, b) 2005, c) 2010.

indicate the poor quality, salinity and high alkalinity of these waters. In effect, the groundwater of the region with a salinity of $2960 \mu \mathrm{m} / \mathrm{cm}$ and an alkalinity of 6.9 is classified in the S2 C4 class of Wilcox classification.

[16], using remote sensing techniques and Landsat satellite imagery, reported the cause of salinity changes in the Central Plateau of Iraq during the 20 years (1990-2010) to be groundwater salinity and arid climate.

The role of the human factor in spreading contamination of water and soil resources and the emergence of fragile ecological conditions in the region is quite evident [20,43]. Inefficient management of land resources, land use changes including the conversion of rangelands to irrigated lands, abandonment of irrigated arable lands due to drop in Karkheh river and groundwater levels as well as the conversion of arable lands to residential lands, livestock and other humaninduced activities over recent years have increased the area of hectares of abandoned fields with no vegetation and the area of saline and erodible soils.

Salt inherited from salt domes in the dry and semi-arid soils of the region should naturally be removed from the soil profile by the irrigation process. 

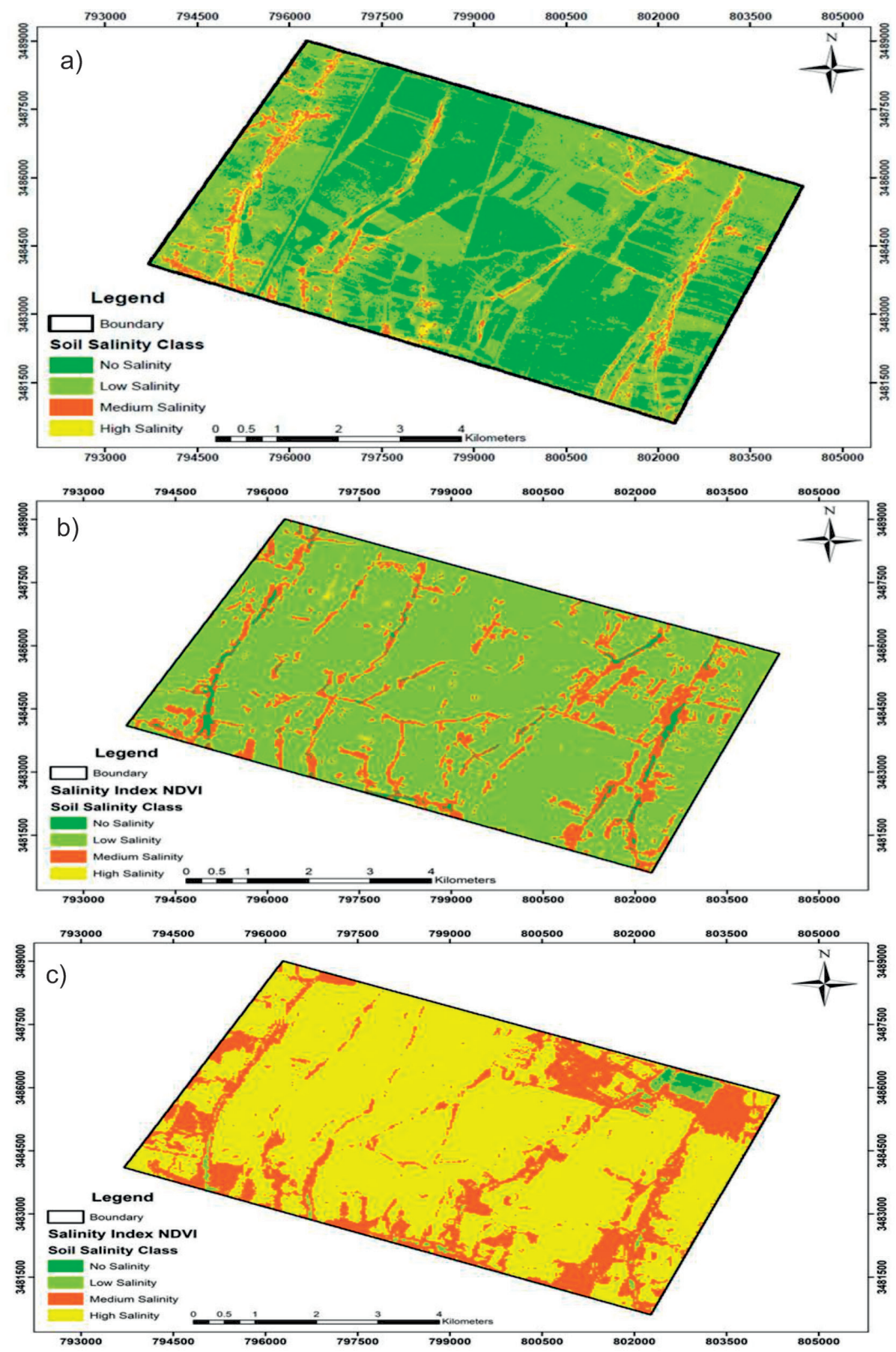

Fig. 6. NDVI index map for the years a) 2000, b) 2005, c) 2010.

The accumulation of these salts in the lower layers and capillary rise in soils with heavy to relatively heavy texture to the surface horizon adversely affect the soils by salinity. Also, in conditions of poor drainage of soils, irrigation can raise the groundwater level to the root development zone and increase salinity and destroy the vegetation. Due to their shallow depth, the drains of Atabiyeh are not able to transfer and discharge excess water from the boundaries of these lands. Moreover, the shallowness of the groundwater level also exacerbates the situation, doubling the problem of secondary salinity in the region in recent years.
What is observed in the Brightness Index maps between 2000 and 2010 (Fig. 5) is the uneven salinity trend in the study area. Mostly, the northern and northeastern sections of the area are less saline than other areas. The existence of a drainage canal in this part of the region to drain water resulting from the rising groundwater and inlet water from the Karkheh River at lower elevation conditions may confirm such a claim.

In the Normalized Difference Vegetation Index salinity index map of the year 2000 (Fig. 6a), the dominance of soil salinity classes for non-saline 
Table 5. Soil salinity changes using satellite imagery for the yaers 2000, 2005 and 2010.

\begin{tabular}{|c|c|c|c|c|c|c|c|c|c|c|}
\hline \multirow{2}{*}{$\begin{array}{c}\text { Percentage } \\
\text { of changes to } \\
\text { total } \\
\left(\mathrm{P}^{\prime}-\mathrm{P}\right)\end{array}$} & \multirow{2}{*}{$\begin{array}{c}\text { Percentage } \\
\text { of changes to } \\
\text { initial area } \\
\mathrm{A} /\left(\mathrm{A}^{\prime}-\mathrm{A}\right)\end{array}$} & \multirow{2}{*}{$\begin{array}{c}\text { Difference } \\
\text { of period } \\
\text { changes } \\
\left(\mathrm{A}^{\prime}-\mathrm{A}\right)\end{array}$} & \multicolumn{2}{|c|}{$\begin{array}{c}\text { Class area in } 2010 \\
\text { indexes }\end{array}$} & \multicolumn{2}{|c|}{$\begin{array}{c}\text { Class area in } 2005 \\
\text { indexes }\end{array}$} & \multicolumn{2}{|c|}{$\begin{array}{c}\text { Class area in } 2000 \\
\text { indexes }\end{array}$} & \multirow{2}{*}{$\begin{array}{l}\text { Salinity } \\
\text { classes }\end{array}$} & \multirow{2}{*}{$\begin{array}{l}\text { Index } \\
\text { Name }\end{array}$} \\
\hline & & & $\begin{array}{l}\text { Percentage } \\
\left(\mathrm{P}^{\prime}\right)\end{array}$ & $\begin{array}{l}\mathrm{Ha} \\
\left(\mathrm{A}^{\prime}\right)\end{array}$ & Percentage & $\mathrm{Ha}$ & $\begin{array}{l}\text { Percentage } \\
\text { (P) }\end{array}$ & $\begin{array}{l}\mathrm{Ha} \\
\text { (A) }\end{array}$ & & \\
\hline-17.58 & -0.86 & -877.12 & 2.93 & 146.43 & 8.57 & 427.41 & 20.52 & 102.552 & S0 & \multirow{4}{*}{ BI } \\
\hline 9.29 & 0.3 & 36.436 & 4.030 & 1996.92 & 3.111 & 1551.78 & 30.74 & 151.555 & S1 & \\
\hline 14.57 & 0.43 & 726.84 & 4.738 & 2431.08 & 3.848 & 1937.43 & 34.16 & 170.245 & S2 & \\
\hline-6.12 & -0.42 & -305.41 & 8.3 & 414.09 & 2.491 & 1071.9 & 14.42 & 719.51 & S3 & \\
\hline 041.12 & -0.99 & -2100.98 & 0.37 & 18.63 & 1.85 & 92.43 & 42.79 & 211.619 & S0 & \multirow{4}{*}{ NDVI } \\
\hline-46.01 & -0.97 & $2295 / 18$ & 1.57 & 78.66 & 8.453 & 4162.86 & 47.59 & 237.843 & S1 & \\
\hline 15.41 & 1.92 & 768.96 & 2.443 & $1169 / 46$ & 1.154 & 96.705 & 8.03 & 400.5 & S2 & \\
\hline 72.86 & 41.83 & 3634.67 & 7.614 & 3721.77 & 0.55 & 27.27 & 1.74 & 86.9 & S3 & \\
\hline
\end{tabular}

(S0 class) and low salinity (S1 class) were $42.49 \%$ and $47.59 \%$, respectively. In 2005 (Fig. 6b), lands with low salinity became more dominant and covered a larger area $(83.45 \%)$. The sharp increase in soil salinity over the five years from 2005 to 2010 (Fig. 6c) is visible on the map of this index. Most of the area was covered by high salinity (74.61\%), while non-saline land covered only a small percentage $(0.37 \%)$. According to the results, changes in soil salinity occurred in parts of the area where degradation, land-use change, and destruction of natural vegetation had happened. According to statistics, from 2000 to 2010, we have 3636.87 hectares $(72.86 \%)$ of saline lands.

The information in Fig. 7 evaluates the total accuracy of the types of supervised classifications of soil salinity indices in Landsat 8 satellite 2015 data. Brightness Index with the highest correlation with soil salinity has the total accuracy of the supervised classification methods by the minimum distance (MD) of $80.58 \%$ with a kappa coefficient of $72 \%$. It also has the highest classification accuracy. Salinity Index 3 with a total accuracy of $45.88 \%$ and kappa coefficient of $25 \%$ had the least accuracy in Mahalanobis classification. It can be said that the minimum distance, maximum likelihood, and Mahalanobis classifications have respectively yielded better results on the accuracy of the index outputs.

One of the weaknesses in the classification of maximum likelihood and Mahalanobis algorithms is the failure to correctly identify pixels in the northern

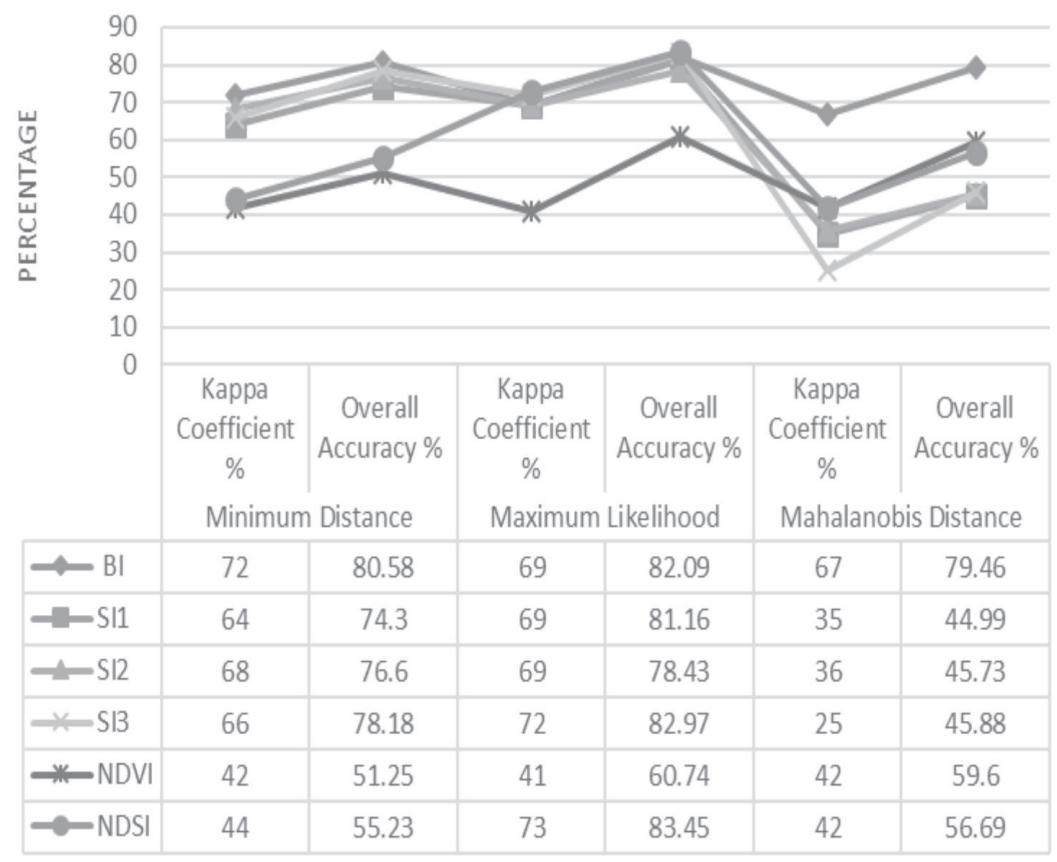

Fig. 7. Total accuracy and Kappa coefficients of the three supervised classification methods in each salinity index for 2015. 
part of the study area. This may be due to the limited vegetation in these areas. Given that the sampling points in the present study were often conducted in the wasteland areas, the determination of different salinity levels by classification algorithms in these areas is more robust.

In other words, since the spectral behavior of the electromagnetic wavelengths for the vegetated areas is distinct from different areas and the actual values of soil electrical conductivity are not determined by sampling, the classification algorithms have hardly been able to determine the salinity degrees using the spectral image. Therefore, it is not unlikely to obtain unrealistic results in vegetation areas, although the amount of crown cover in this area is low and at the same time measurable. This problem is also partially shown in the maps obtained from the classification results. Soils in most areas with limited vegetation (northern parts of the region) are classified as no salinity or low salinity, which is not necessarily correct. One of the solutions to this problem is soil-independent re-sampling in vegetated areas to provide more accurate salinity levels for these areas by selecting new training data for these areas [46].

The use of a supervised classification by the minimum distance method produced good accuracy in separating the different soil salinity classes in all six indices. The comparison of maps obtained from salinity classes in the two Brightness Index and Normalized Difference Vegetation Index indices of 2015 (Fig. 8)
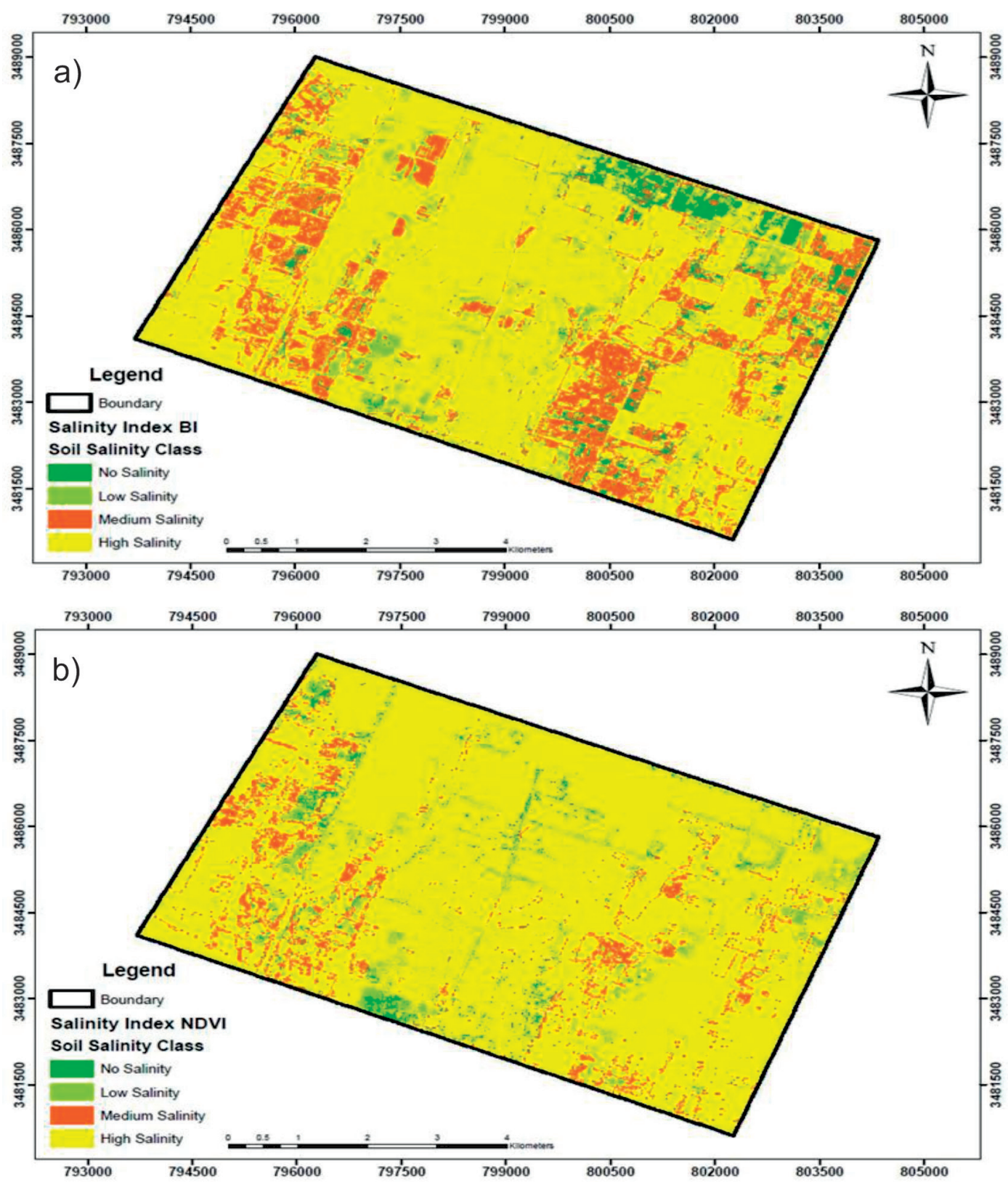

Fig. 8. Salinity map of the soils in the study area by the minimum distance classification method in the top indices using Landsat 8 satellite imagery in 2015. a-BI index and b-NDVI index. 
shows a non-uniform pattern of the salinity intensity distribution in the study area.

The relative higher salinity severity in the central, western, and eastern regions than in the northern regions, maybe due to more significant drainage weakness and higher groundwater levels. Although soil electrical conductivity is subject to various factors such as soil texture, adverse climatic conditions, geological formations, and low geomorphology in the study area, one of the factors contributing to the increase in electrical conductivity is the accumulation of soluble salts in the soil resulting from severe evaporation of groundwater as well as the poor drainage of the area.

Due to the fact that the groundwater level of these areas has even fallen to less than $1 \mathrm{~m}$ in recent years and the salt concentration in the adjacent areas of the Karkheh River is high enough that the salt crusts are clearly present in these areas, it is very likely that the soluble salts of the river have spread to the soils in the region and adjacent areas. The salinity of Atabieh's soils is thus likely to be due to the same factors. However, defining the root causes of soil salinity in this area requires more in-depth geological and geomorphological studies as well as the access to the climatic and historical maps of the area that are not relevant to the present study $[22,26,46]$.

X-ray diffraction method and band composition of 4, 5 and 7 band 8 satellites were used to determine the type and frequency of minerals in the studied soils. Fig. 9a) shows the evaporite mineral peaks of saline

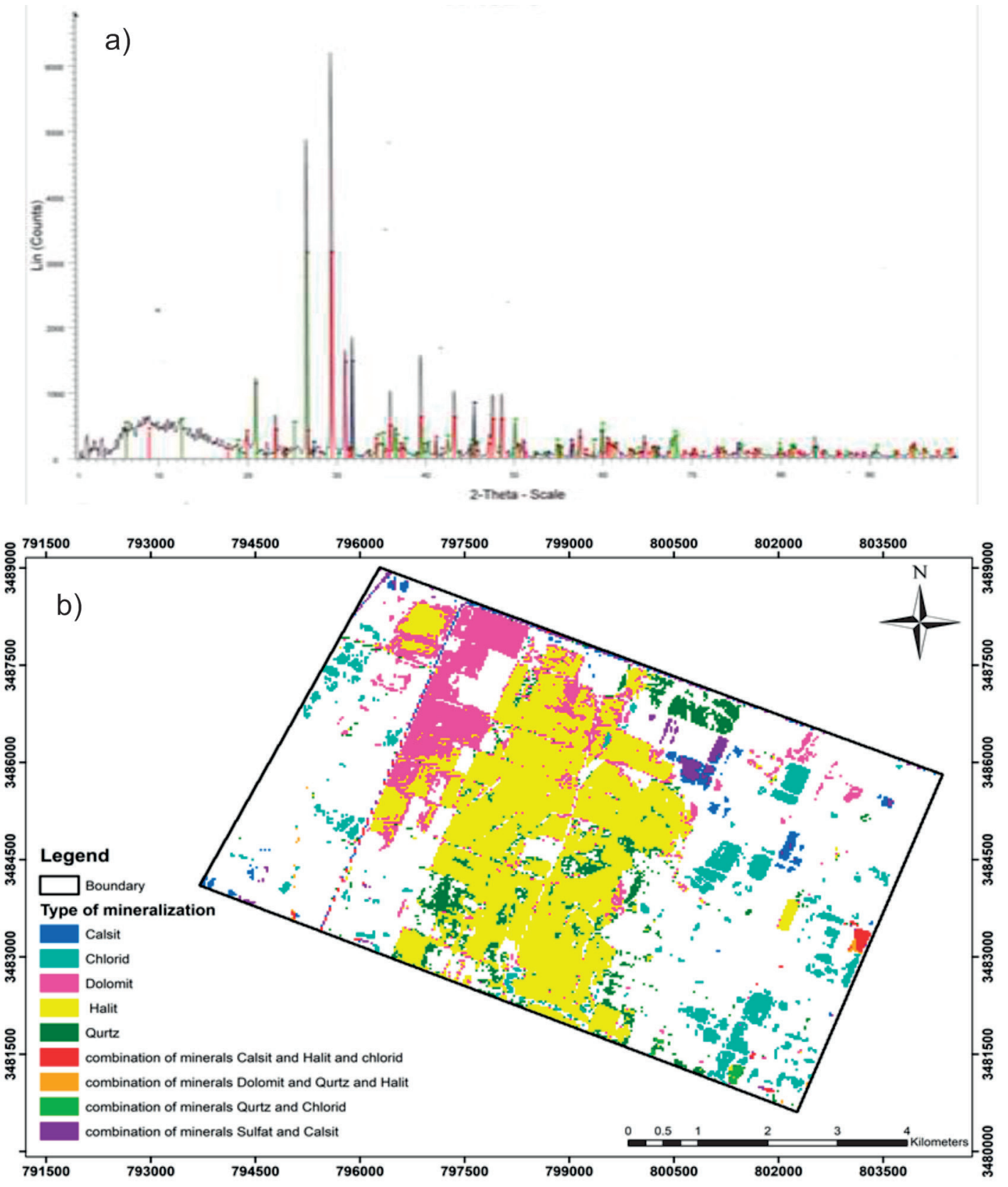

Fig. 9. Identification of saline minerals a- by X-ray diffraction and b- using Landsat 8 satellite images of 2015. 
soils in the study area. In turn, Fig. 9b) shows the estimation of diversity and the amount of minerals with satellite images in the study area. XRD data analysis results indicate the presence of halite $(\mathrm{NaCl})$, calcite $\left(\mathrm{CaCO}_{3}\right)$, quartz $\left(\mathrm{SiO}_{2}\right)$, clay minerals, dolomite $(\mathrm{CaMg}$ $\left.\left(\mathrm{CO}_{3}\right)_{2}\right)$ and feldspars $(\mathrm{Na}, \mathrm{Ca})$ in the study area as the dominant minerals which are consistent with most of the minerals in the satellite images.

In the mineralogical composition of saline soils of West Texas by the XRD method, Halite, Gypsum $\left(\mathrm{CaSO}_{4} \cdot 2 \mathrm{H}_{2} \mathrm{O}\right)$, Thenardite $\left(\mathrm{Na}_{2} \mathrm{SO}_{4}\right)$, and Blodite $\left(\mathrm{Na}_{2}\right.$ $\mathrm{Mg}\left(\mathrm{SO}_{4}\right)_{2} \quad\left(4 \mathrm{H}_{2} \mathrm{O}\right)$ minerals were found. However, the same study in the non-saline soils of Lake Silver indicated the existence of quartz, calcite, and dolomite minerals [47]. The presence of calcite and dolomite minerals in these soils is justified due to their calcareous origin from the parent rocks and upstream flood deposits. Evaporite halite minerals (especially chlorite halites) which occupy a large area in the study area (Fig. 9b) and feldspar have also been introduced into the soil due to salinity of groundwater resources, high evaporation, and the presence of salt domes in the alluvial sediments of the river. Moreover, their production is constantly increasing under extreme salinity conditions.

Usually, saline soils in dry areas, especially when salt crust forms on the soil surface, show high spectral reflectance. Studies on gypsum, $\mathrm{NaCl}$, and kaolinite in laboratory-controlled conditions indicate that the gypsum is detectable in a $2.2 \mathrm{~mm}$ area, consistent with the center of the Landsat 7 satellite band, with a strong adsorption region. $\mathrm{NaCl}$, in turn, reflects more in the range, consistent with Landsat satellite bands than gypsum [45].

Quartz is part of the minerals in the silt and sand sections of the soil [48], but because of its clay particle size, it has been identified in mineralogical results with a peak of 3.33. The dominant silicate clay minerals in Khuzestan saline soils include Illite, Chlorite, Smectite, Palygorskite, and Kaolinite, with predominant calcareous and herbaceous parent materials. The amount of these minerals will vary depending on soil salinity and alkalinity, drainage strength or weakness, different land uses, leaching rates, and so on.

The composition of soluble ions in groundwater and the high amounts of magnesium, calcium, sodium, and low levels of aluminum and iron in it play a significant role in the stability, evolution, or reconstitution of these clay minerals. Abundant magnesium, salinity, and alkalinity (high $\mathrm{pH}$ ) in underground water and inadequate drainage of soils lead to in situ formation as well as the deposition of smectite minerals from river water suspension which are usually transferred to adjacent soils.

The composition of soluble ions in groundwater and the high amounts of magnesium, calcium, sodium and low levels of aluminum and iron in it play a major role in the stability, evolution or reconstitution of these clay minerals. Abundant magnesium, salinity and alkalinity (high $\mathrm{pH}$ ) in underground water and inadequate drainage of soils lead to in situ formation as well as the deposition of smectite minerals from river water suspension which are usually transferred to adjacent soils.

The increase in the amount of magnesium and calcium ions in the satellite image and the predominance of dolomite evaporite mineral after halite confirm such a claim. Palygorskite has also been reported in most of Khuzestan soils due to evaporative conditions in saline areas, increasing magnesium to calcium ratio in soil solution and increasing $\mathrm{pH}$ [26]. The remarkable presence of this filamentous mineral at the soil surface is due to wind erosion and dust from Khuzestan province dust centers and those of neighboring countries [49].

\section{Conclusions}

The results of this study showed that Brightness Index is more desirable than other indices in detecting soil salinity levels. In turn, Normalized Difference Vegetation Index has been effective in determining salinity of the area due to its important role in vegetation estimation. Examination of soil salinity trends between 2000 and 2015 revealed that saline land class changes were such that most of these lands became saline lands during these 15 years so that the area of lands with no salinity and low salinity classes decreased; on the contrary, the area of lands with medium to high salinity increased.

Based on the salinity indices, it can be said that the salinity trend has progressed from the southern and central parts to the northern parts. This trend was distributed in almost all the study areas in 2015 . Atabieh area, located south of Dasht-e Azadegan and northeast of Hoveizeh in Khuzestan province, has saline soils due to low altitude, inadequate drainage, and high groundwater. In effect, the closer we get to the drained areas in the north of the region, the slower and less salient the salinity trend has become over time.

Although the parent materials of soils in the study area are alluvial sediments having salinity from the salt domes in their passage from the upstream of the Karkheh River, the secondary salinity is evident in almost all areas in the region. Over the past decades, the low efficiency of water transfer structures, overirrigation and irrigation water infiltration losses as well as reduced quality of irrigation water resulting from changes in the water quality of the Karkheh River, along with the changes in the cultivation patterns contrary to the patterns proposed for cultivation in the region, have led to the accumulation of salts in the soils of the study area.

Moreover, inappropriate location of irrigation and drainage canals due to the percentage of slope and the bottom line of the region are other determining factors in soil salinity in the region. Indeed, though drainage canals are established in some parts of the region, 
there is an increase in surface soil salinity due to water leakage and groundwater recharge from the surrounding drainage canals.

Thus, if remote sensing imagery is available, it can provide relatively accurate maps for a limited number of points at a low cost (especially in areas affected by salinity). These maps can, in turn, be used optimally in salinity monitoring and farm management. In effect, by applying advanced regression models, in all areas where sampling is not performed, their salinity is estimated based on the pixel digital value.

Establishing a proper drainage network for the cultivation of salt-tolerant plants is, thus, a necessity. Due to high water level of the groundwater table and high evapotranspiration from the soil surface, postharvest strategies are needed to decrease the amount of evapotranspiration from the soil and the accumulation of salt in the soil. Future studies can examine the use of other remote sensing techniques such as feature selection methods to select bands with maximum information to achieve higher accuracy in salinity mapping.

Landsat satellite thermal bands can also be used to monitor saltwater leaks from irrigation and drainage canals. Differences in temperature between dry and wet soils can be used to monitor the quality of irrigation and drainage systems and to determine the source of primary or secondary soil salinity.

\section{Acknowledgements}

The authors would like to acknowledge the valuable comments and suggestions of the reviewers, which have improved the quality of this paper.

\section{Conflict of Interest}

The authors declare that there is no conflict of interest regarding the publication of this paper.

\section{References}

1. SHRIVASTAVA P., KUMAR R. Soil salinity: a serious environmental issue and plant growth promoting bacteria as one of the tools for its alleviation. Saudi journal of biological sciences. 22, 123, 2015.

2. LETEY J., HOFFMAN G.J., HOPMANS J.W., GRATTAN S.R., SUAREZ D., CORWIN D.L., OSTER J.D., WU L. AMRHEIN C. Evaluation of soil salinity leaching requirement guidelines. Agricultural water management. 98, 502, 2011.

3. ELHAG M., BAHRAWI J.A. Soil salinity mapping and hydrological drought indices assessment in arid environments based on remote sensing techniques. Geoscientific Instrumentation, Methods and Data Systems. 6, 149, 2017.

4. ASFAW E., SURYABHAGAVAN K., ARGAW M. Soil salinity modeling and mapping using remote sensing and GIS: The case of Wonji sugar cane irrigation farm, Ethiopia. Journal of the Saudi Society of Agricultural Sciences. 17, 250, 2018.

5. ALLBED A., KUMAR L. Soil salinity mapping and monitoring in arid and semi-arid regions using remote sensing technology: a review. Advances in remote sensing. 2 (4), 373, 2013.

6. ALLBED A., KUMAR L., ALDAKHEEL Y.Y. Assessing soil salinity using soil salinity and vegetation indices derived from IKONOS high-spatial resolution imageries: Applications in a date palm dominated region. Geoderma. 230-231, 1, 2014.

7. ABBAS T., RIZWAN M., ALI S., ADREES M., ZIA-URREHMAN M., QAYYUM M.F., OK Y.S., MURTAZA G. Effect of biochar on alleviation of cadmium toxicity in wheat (Triticum aestivum L.) grown on Cd-contaminated saline soil. Environmental Science and Pollution Research. 25, 25668, 2018

8. BANNARI A., EL-BATTAY A., BANNARI R., RHINANE H. Sentinel-MSI VNIR and SWIR bands sensitivity analysis for soil salinity discrimination in an arid landscape. Remote Sensing. 10 (6), 855, 2018.

9. CHEN J., MUELLER V. Coastal climate change, soil salinity and human migration in Bangladesh. Nature Climate Change. 8, 981, 2018.

10. ABDEL-FATTAH G.M., ASRAR A.W. A. Arbuscular mycorrhizal fungal application to improve growth and tolerance of wheat (Triticum aestivum L.) plants grown in saline soil. Acta Physiologiae Plantarum. 34, 267, 2012.

11. VASILAKOGLOU I., DHIMA K., KARAGIANNIDIS N., GATSIS T. Sweet sorghum productivity for biofuels under increased soil salinity and reduced irrigation. Field Crops Research. 120, 38, 2011.

12. SHAINBERG I., SHALHEVET J. Soil salinity under irrigation: Processes and management. Springer Science \& Business Media. 2012.

13. AHMED B.O., INOUE M., MORITANI S. Effect of saline water irrigation and manure application on the available water content, soil salinity, and growth of wheat. Agricultural Water Management. 97, 165, 2010.

14. WICHELNS D., QADIR M. Achieving sustainable irrigation requires effective management of salts, soil salinity, and shallow groundwater. Agricultural Water Management. 157, 31, 2015.

15. WU W., MHAIMEED A.S., AL-SHAFIE W.M., ZIADAT F., DHEHIBI B., NANGIA V., DE PAUW E. Mapping soil salinity changes using remote sensing in Central Iraq. Geoderma Regional. 2-3, 21, 2014,.

16. GONG L., RAN Q., HE G., TIYIP T. A soil quality assessment under different land use types in Keriya river basin, Southern Xinjiang, China. Soil and Tillage Research. 146, 223, 2015.

17. RASEL H., HASAN M., AHMED B., MIAH M. Investigation of soil and water salinity, its effect on crop production and adaptation strategy. International Journal of Water Resources and Environmental Engineering. 5, 475, 2013.

18. MACHADO R.M.A., SERRALHEIRO R.P. Soil salinity: effect on vegetable crop growth. Management practices to prevent and mitigate soil salinization. Horticulturae. 3, 30, 2017.

19. PENG J., BISWAS A., JIANG Q., ZHAO R., HU J., HU B., SHI Z. Estimating soil salinity from remote sensing and terrain data in southern Xinjiang Province, China. Geoderma. 337, 1309, 2019. 
20. CHHABRA R.. Soil salinity and water quality. Routledge. 2017.

21. HAMZEH S., NASERI A.A., ALAVIPANAH S.K., MOJARADI B., BARTHOLOMEUS H.M., CLEVERS J.G., BEHZAD M. Estimating salinity stress in sugarcane fields with spaceborne hyperspectral vegetation indices. International Journal of Applied Earth Observation and Geoinformation. 21, 282, 2013.

22. ALAVIPANAH S.K., DAMAVANDI A.A., MIRZAEI S., REZAEI A., HAMZEH S., MATINFAR H.R., TEIMOURI H., JAVADZARRIN I. Remote sensing application in evaluation of soil characteristics in desert areas. Natural Environment Change. 2 (1), 1, 2016.

23. SUWEIS S., RINALDO A., VAN DER ZEE S., DALY E., MARITAN A., PORPORATO A. Stochastic modeling of soil salinity. Geophysical Research Letters. 37 (7), 2010.

24. PANASKAR D., WAGH V., MULEY A., MUKATE S., PAWAR R., AAMALAWAR M. Evaluating groundwater suitability for the domestic, irrigation, and industrial purposes in Nanded Tehsil, Maharashtra, India, using GIS and statistics. Arabian Journal of Geosciences. 9, 615. 2016.

25. JAAFARI A., MAFI-GHOLAMI D., THAI PHAM B., TIEN BUI D. Wildfire probability mapping: bivariate vs. multivariate statistics. Remote Sensing. 11 (6), 618, 2019.

26. IVUSHKIN K., BARTHOLOMEUS H., BREGT A. K., PULATOV A., FRANCESCHINI M.H., KRAMER H., VAN LOO E.N., ROMAN V.J., FINKERS R. UAV based soil salinity assessment of cropland. Geoderma. 338, 502, 2019.

27. ELHAG M. Evaluation of different soil salinity mapping using remote sensing techniques in arid ecosystems, Saudi Arabia. Journal of Sensors. 2016, 2, 2016.

28. YU H., LIU M., DU B., WANG Z., HU L., ZHANG B. Mapping soil salinity/sodicity by using Landsat OLI imagery and PLSR algorithm over semiarid West Jilin Province, China. Sensors. 18 (4), 1048, 2018.

29. KHAN W., AZIZ T., MAQSOOD M., FAROOQ M., ABDULLAH Y., RAMZANI P., BILAL H. Silicon nutrition mitigates salinity stress in maize by modulating ion accumulation, photosynthesis, and antioxidants. Photosynthetica. 56, 1047, 2018.

30. HATEFFARD F., DOLATI P., HEIDARI A., ZOLFAGHARI A.A. Assessing the performance of decision tree and neural network models in mapping soil properties. Journal of Mountain Science. 16, 1833, 2019.

31. FU B., SHI P., FU H., NINOMIYA Y., DU J. Geological Mapping Using Multispectral Remote Sensing Data in the Western China. In IGARSS 2019-2019 IEEE International Geoscience and Remote Sensing Symposium. 5583-5586, 2019 IEEE

32. ZARASVANDI A., CARRANZA E., MOORE F., RASTMANESH F. Spatio-temporal occurrences and mineralogical-geochemical characteristics of airborne dusts in Khuzestan Province (southwestern Iran). Journal of geochemical exploration. 111, 138, 2011.

33. CHAMANNEJADIAN A., MOEZZI A., SAYYAD G., JAHANGIRI A., JAFARNEJADI A. Spatial distribution of lead in calcareous soils and rice seeds of Khuzestan, Iran. Malaysian journal of soil science. 15, 115, 2011.

34. DAYANI M., JAFARI S., KHALILMOGHADAM B., DEHGHANI A. Saline and Sodic mapping using Geostatistics Theory (A case study in western Karoon river land of Khozestan). Watershed Management Research. 94, 86, 2012.

35. FERNANDEZ-BUCES N., SIEBE C., CRAM S., PALACIO J. Mapping soil salinity using a combined spectral response index for bare soil and vegetation: A case study in the former lake Texcoco, Mexico. Journal of Arid Environments. 65 (4), 644, 2006.

36. ZARCO-TEJADA P.J., USTIN S., WHITING M. Temporal and spatial relationships between within-field yield variability in cotton and high-spatial hyperspectral remote sensing imagery. Agronomy Journal. 97 (3), 641, 2005.

37. QI J., CHEHBOUNI A., HUETE A., KERR Y., SOROOSHIAN S. A Modified Soil Adjusted Vegetation Index. Remote Sensing of the Environment, 119, 1994.

38. GITELSON A., STARK R., GRITS U., RUNDQUIST D., KAUFMAN Y., DERRY D. Vegetation and soil lines in visible spectral space: a concept and technique for remote estimation of vegetation fraction. International Journal of Remote Sensing. 23, 2537, 2002.

39. AHMADI A., KAZEMI A., TORANJZAR H. Comparison of spectrum indices for mapping soil salinity in saline lands of Chezan plain (Markazi province). Desert. 23, 211-, 2018.

40. TAJGARDAN T., AYOUBI S.A., SHATAEI J.S., KHORMALI F. Mapping soil surface salinity using remote sensing data of ETM+ (case study: north of Agh ghala, Golestan province). Ournal of water and soil conservation (journal of agricultural sciences and natural resources). 16 (2), 1, 2009.

41. MOKARRAM M., HOJJATI M., ROSHAN G., NEGAHBAN S. Modeling the behavior of Vegetation Indices in the salt dome of Korsia in North-East of Darab, Fars, Iran. Modeling Earth Systems and Environment. 1, 27, 2015.

42. GORJI T., SERTEL E., TANIK A. Monitoring soil salinity via remote sensing technology under data scarce conditions: A case study from Turkey. Ecological Indicators. 74, 384, 2017.

43. HU J., PENG J., ZHOU Y., XU D., ZHAO R., JIANG Q., SHI Z. Quantitative estimation of soil salinity using UAVborne hyperspectral and satellite multispectral ima-ges. Remote Sensing, 11 (7), 736, 2019.

44. AMINI D., TAVAKOLI M., ROSTAMINYA M. Mapping Spatial Variability of Soil Salinity Using Remote Sensing Data and Geostatistical Analysis: A Case of Shadegan, Khuzestan. Environmental Erosion Research Journal. 7 28(4)), 24, 2018.

45. TAGHADOSI M.M., HASANLOU M., EFTEKHARI $\mathrm{K}$. Evaluating and comparing supervised classification algorithms With the aim of mapping soil salinity levels using Sentinel-2 satellite imageries. 28 (110), 37, 2019.

46. ALDABAA A.A.A., WEINDORF D.C., CHAKRABORTY S., SHARMA A., LI B. Combination of proximal and remote sensing methods for rapid soil salinity quantification. Geoderma. 239, 34, 2015.

47. KARIMI A., KHADEMI H., JALALIAN A. Genesis and distribution of palygorskite and associated clay minerals in soils and sediments of southern Mashhad. Iran. J. Crystallography and Mineralogy. 16, 545, 2009.

48. CHOROM M., BAGHERNEJAD M., JAFARI S. Influence of rotation cropping and sugarcane production on the clay mineral assemblage. Applied Clay Science. 46 (4), 385, 2009. 